\title{
Experimental Development of CE Piston with Controlled Bore and Elimination of Bore Oversize
}

\author{
Giridharan, Ayyasamy, Vignesh S., Jothiraj P.
}

\begin{abstract}
In day to day life modern vehicle with petrol engines are provided with different compensating devices for fuel and air mixture supply. Even there exists a problem of high fuel consumption owing to many factors, one of which is the manufacturing defect of carburetor. Actual size of the piston bore would be 30,000 microns. Due to the use of multipoint tool, the dimension changes which may probably increase or reduce by 30 microns which is normally observed in all processes. The project is about completely eliminating or reducing the piston bore over size problem which occur while using multipoint cutting tool this can be done by introducing single point cutting tool. By doing this we can eliminate piston bore bulge in boring machine process.
\end{abstract}

Keywords : Combustion, Engine, Piston Bore, Oversize reduction.

\section{INTRODUCTION}

$\mathrm{N}$ owadays vehicles are making using of carburetors for mixing up exact amount of fuel with air so that IC engine works perfectly. The fuel is stored and supplied to cylinder where it is mixed with air combusted energy mixed with air combusted energy is produced. The fuel which is stored is fuel tank is pumped and delivered through fuel filter with help of fuel lines to carburetors. In India carburetors and fuel pumps manufactured by UCAL FUEL SYSTEM limed from 1985. In 1987 Mikuni corporations of Japan as joined with Ucal fuel system. In 1989 Ucal converted into public limited. Air and fuel has mixed inside the carburetors and supplied to the engine pressure drop has happening inside carburetors air and fuel mixture. During ideal condition carburetors will send exact amount of engine. During different condition that involve to variations to physical conditions to achieving the fuel ratio the physical conditions inside the intake manifold due to fast throttle opening and closing to the boring side.In Boring process produce the circular internal profile to on a hole made by drilling process or another process. After boring to go with the surface

Revised Manuscript Received on December 05, 2019.

* Correspondence Author

Giridharan, Department of Mechanical Engineering, Kalasalingam, Academy of Research and Education, Krishnankoil, India

Ayyasamy , Department of Mechanical Engineering, Kalasalingam, Academy of Research and Education, Krishnankoil, India

Vignesh S.*, Department of Mechanical Engineering, Kalasalingam, Academy of Research and Education, Krishnankoil, India

Jothiraj P., Department of Mechanical Engineering, Kalasalingam, Academy of Research and Education, Krishnankoil, India finished to made by the special purpose boring machine. In this machine normally they are operated multipoint tool. There was a problem made carburetors to piston size over sizing to the boring operation. There is single point tool is called boring bar in boring bar can be rotated or job is rotated. Even there is Machine tools which rotate the boring bar against a stationary work piece are called boring machines. The main goal of this paper is to find the factor for assessing reducing waste of carburetors. So we prepare questionnaire based on literature reviews and knowledge from industrial experts. The main part of this project is finding factors, for that we discuss with the industrial experts, literature reviews and decision makers of a corresponding industry.

The project is about completely eliminating or reducing the piston bore over size problem which occur while using multipoint cutting tool this can be done by introducing single point cutting tool. By doing this we can eliminate piston bore bulge in boring machine process. Relevant literature is sorted into two sub-sections namely (a) Boring tools (1983) (b) Tool support and drilling tool (1982)(c) Air valve type carburetor and method of construction (1974)

(a) Boring tools(1983):

Grafe W, Help P (1983)told about the additional of cutter bits which can be rotatable or stationary movable one with the boring tool, in the tool holder or tool shank the cutter bit is fixed close to the central axis. This has the main advantage of avoiding damage to the tool or breakage in the central axis of main cutting edge. This also improves the tool life and cost efficient one. Due to lager diameter of boring tool there may be some increase in tolerance of self-centering and this additional cutter bit provides the self-centering of boring tool.

(b) Toll support and drilling tool (1982):

Martins. J evaluated and explained about the tool support which tends to reduce the breakage of tool. It is said about the art of drilling and drilling support where the centre drill gets additional cutter edges by cutting radially extended cutting edges which are removable mounted. Since the cutting edges are high, heat production increases and to reduce those cooling lubricants are allowed to flow towards the drilling hole. He also said that there is another disadvantage, time loss happens during tool change but they can be compensated by operational cost. 
(c) Air valve type carburetor and method of construction (1974):

Kawai I, Uchida T, Ishima I explained about the air-valve carburetor and its construction. Air-valve carburetors are also catalytic converters used in two-wheelers. The suction piston is mounted in suction chamber of the main body of the carburetor. In that chamber due to suction pressure the piston tends to slidingly projected or retracted. In that air passage jet needle is fixed in the suction piston and fuel nozzle is fixed in the main body. The jet needle helps in controlling fuel metering area by varying it by attached pin which is moved in and out of nozzle. The jet needle and nozzle are relatively positioned such that main body and the suction chamber of the carburetor. By centering the jet needle relative to the nozzle there will be uniformity in flow rate of fuel from the carburetor.

\section{PROBLEM DESCRIPTION}

In machining process of carburetor boring plays a main role. In this we found that due to the use of multipoint cutting tool occurrence of the defect has a high probability. Due to this the quality of the product decreases. Usually the defect in the piston bore will be on or around 30 microns so we decided to use single point cutting tool which reduced this defect so that we can improve the quality.

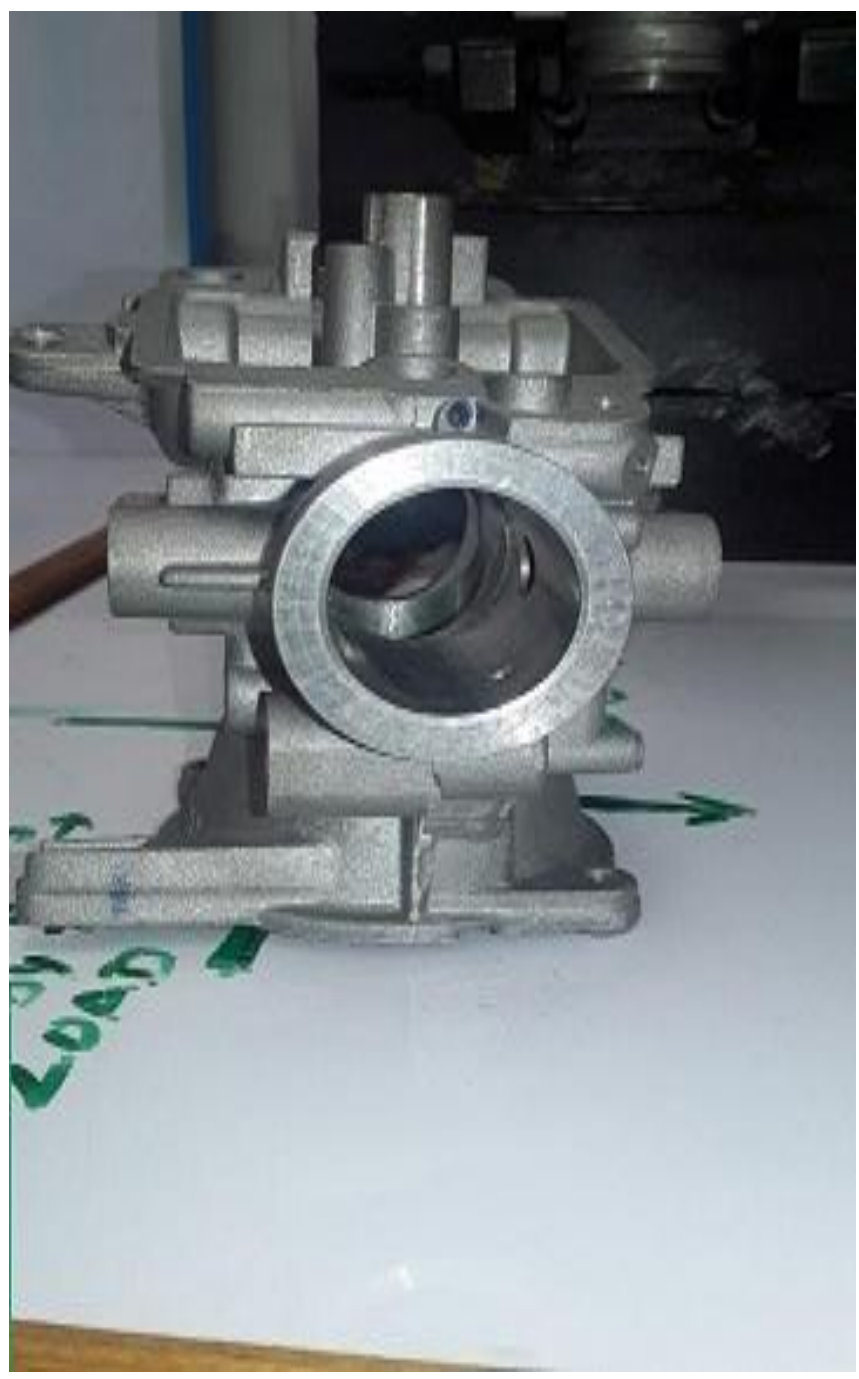

Fig.1 Defective Carburetor

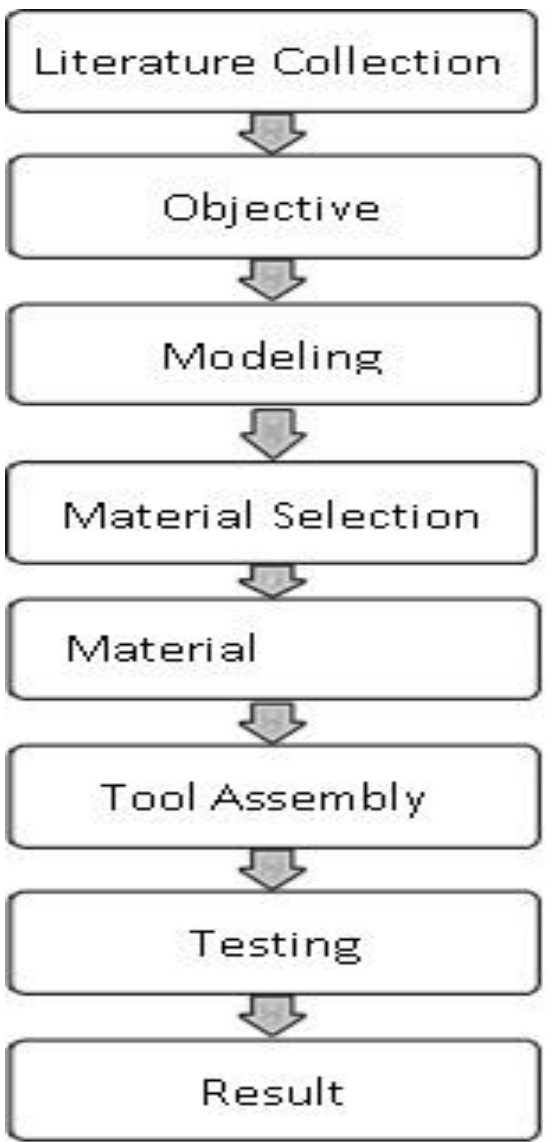

Fig.2. Methodology

\section{Production Process}

Production plan planned by a smorgasbord of departments finally reaches this department and the plan will be executed accordingly. As the condition and availability of workers are known by this department cycle time and the number of workers are planned here. Supervisors are allotted for all the lines ( 4 wheeler, 3 wheeler, 2 wheeler and ASV). Monitoring of production is done here.

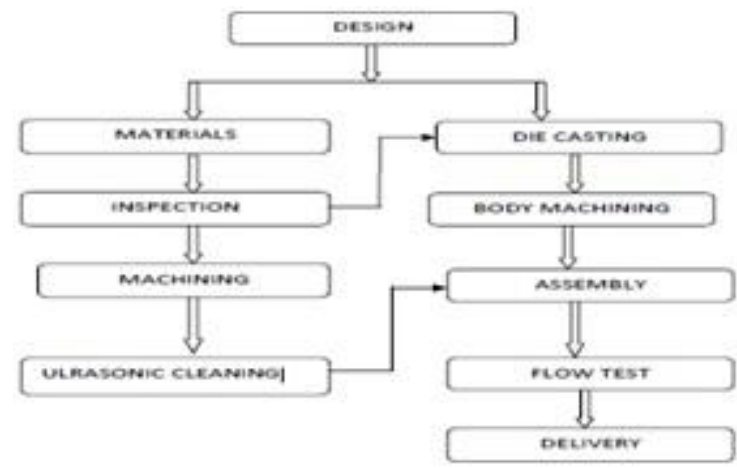

Fig.3. Production Process Plan

\section{Boring Machine}

Boring machine is used to boring holes in large and small diameter of the heavy parts, such as steam engine cylinders, machine housing. There are well aware of impossible to holding and rotate in an special purpose machine and fine boring machine. By using the simple attachments boring machine can be used for facing turning, grinding, gear cutting. It can be horizontal or vertical according to the

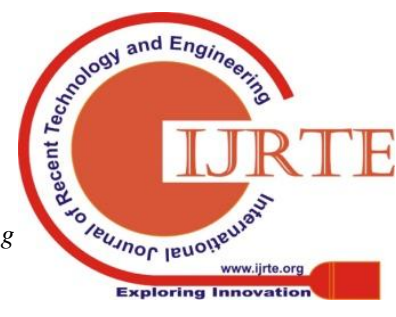


oriental axis of rotation of the machine spindle.

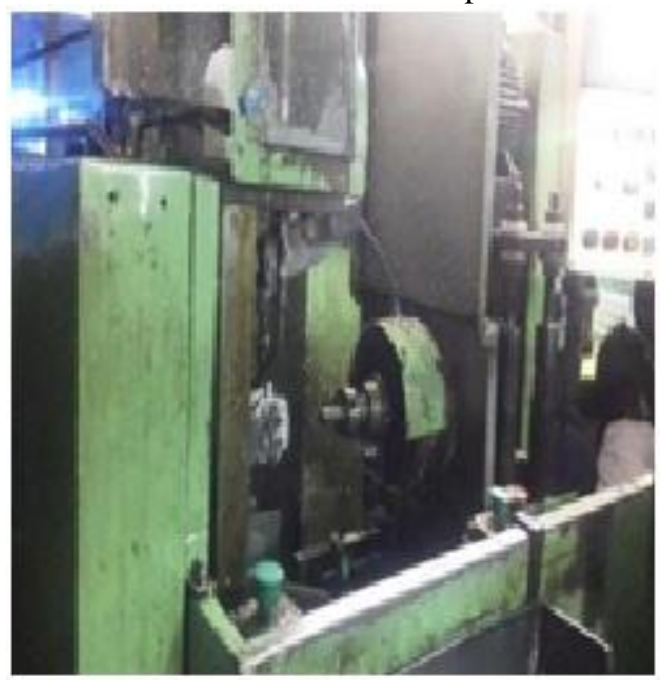

Fig.4. Special Purpose Machine

\section{Specification of Boring Machine}

The specification of the boring machine can be understood from the following Table -I given below.

Table-I: Specifications

\begin{tabular}{|c|c|c|}
\hline Item Code No & ABM - AM-1250 & ABM - AM-1251 \\
\hline Boring Range & $64-140 \mathrm{~mm}$ & $63-100 \mathrm{~mm}$ \\
\hline Boring Capacity & $39-200 \mathrm{~mm}$ & $38-150 \mathrm{~mm}$ \\
\hline $\begin{array}{c}\text { Maximum Boring } \\
\text { Depth }\end{array}$ & $500 \mathrm{~mm}$ & $300 \mathrm{~mm}$ \\
\hline $\begin{array}{c}\text { Spindle Speed Range } \\
\text { Surface Table }\end{array}$ & $\begin{array}{c}172-205-258-308-420 \\
\mathrm{RPM}\end{array}$ & $500-400 \mathrm{step} \mathrm{less}$ \\
\hline Height & $1075 \times 400 \mathrm{~mm}$ & $300-700 \mathrm{~mm}$ \\
\hline Weight (Approx) & $2400 \mathrm{~mm}$ & $1780 \mathrm{~mm}$ \\
\hline Base Area & $1650 \times 1400 \mathrm{~mm}$ & $1200 \times 920 \mathrm{~mm}$ \\
\hline
\end{tabular}

\section{MODELING AND MATERIAL SELECTION}

\section{Modeling}

In this modeling we created the $3 \mathrm{~d}$ model of the cutting tool in single point tool by using solid works version 2016.In this software we used to created modeling in comment line, extrude, trim, etc.

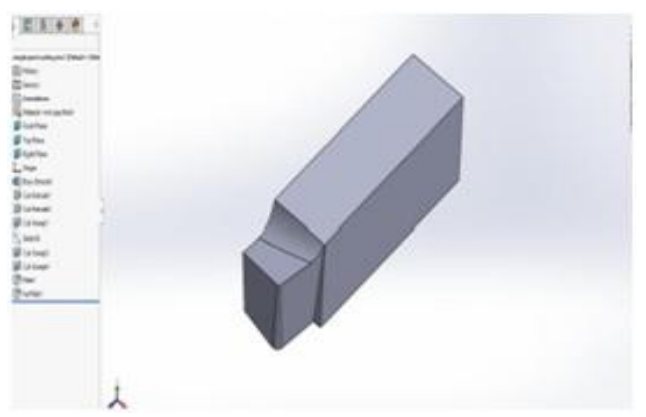

Fig.5. Modeling of Tool

\section{Materials Selection}

\section{Ceramics:}

Carbide, ceramics has to be equal combination of cubic boron, nitride and diamond, does have high hardness than High speed steel allow the faster material removal than High speed steel in most of the cases. These materials are exorbitant to compare with brittle than steel, then the body of the cutting tool is made up of steel, and a small cutting edge to made of the hard material has attached. In this cutting edge is usually clamped on brazed on to a steel is this is usually only done for carbide.

\section{Tool materials:}

In tool materials order to remove burr from a job, in a cutting tool can be harder than the job piece and must contain a cutting edge at the high operating temperature produced by the friction in cutting action.

\section{Carbon steel:}

Steel with a carbon content range from 1 to $1.2 \%$ was the materialused in boring bar. Tools made up these carbon steel are comparatively high expensive, it tend tobe lose machining ability at temperatures at about $205^{\circ} \mathrm{C}$.

\section{Multipoint cutting tool:}

It contains more than two main cutting edges that similarly engage in cutting action in a move. Even though, cutters with two cutting edges are also considered multi-point cutting tools instead of considered as a double point cutter. There are number of cutting edges present in a multi-point cutting edge may varying from few hundreds. The cutting edge appears in the intersection of rake and flank surface, set of rake surface and flank surface also exists for each cutting point.

\section{Single point cutting tool :}

Single point cutting tool have one main cutting edge.It can perform material removal process at a time in one single move. In this tool has to be pitch circle diameter of piston bore have the tool selection in accurate way of process.

\section{TESTING}

We have tested in special purpose boring machine to eliminate the piston bore oversize by using single point tool. Already used in this machine tool has multipoint tool. Due to the use of multipoint tool dimension changes increase or reduce by 30 microns. We analyze and change the tool for surface finishing to using single point tool.

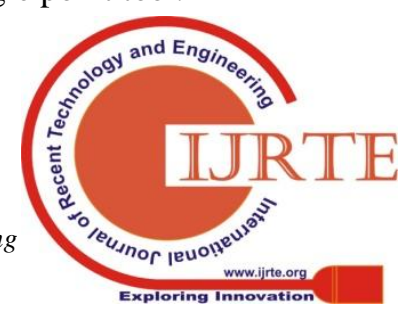




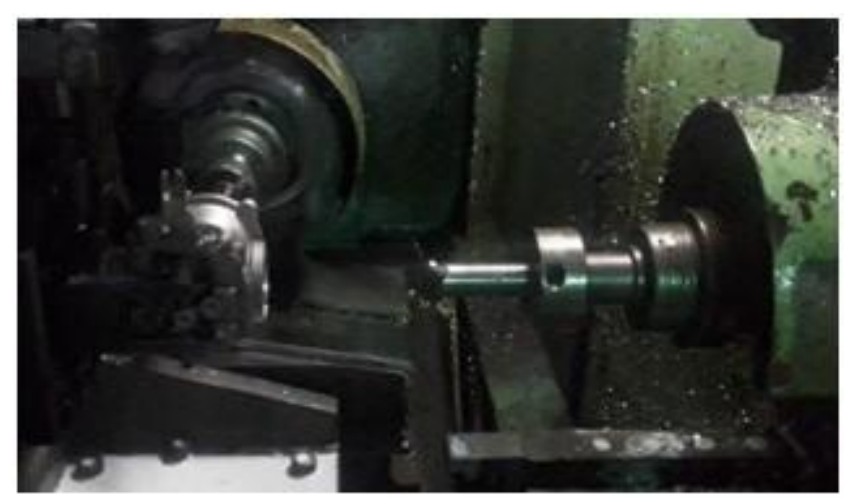

Fig.6 Testing

\section{RESULTS AND DISCUSSIONS}

Status Before Implementation: Piston bore getting bulge up to specification 30 micron

Status After Implementation: Piston bore has no significant bulging from tool selection changed (multi point cutting to single point cutting PCD). The factor affecting for machining process are assessed by using elimination and choice translating technique. Here we have eliminated piston bore over size bulging from per month 176 nos. Instead of multipoint tool we have changing single point tool cost saving upto cpc -1.33 to 0.046 INR

Cost Estimation:

The cost is estimated using the relation below:

Cost Estimation $=$ Tool Cost/Quantity Produced

Tool cost $=$ INR.7980 (approx.)

Quantity produced in one shift $=1000$ nos

In one day we are operating machine for 3 shifts $=3000$ nos In every two days has changing tool to eliminate the piston bore over size

2 days (Quantity of carburetor) $=2 \times 3000=6000$ nos

Therefore Cost estimation=INR 1.33

\section{CONCLUSIONS}

From this study, we have observed that the effect of the mentioned factors played an important role in UCAL fuel system industry where industry is looking for few methods and innovative techniques (KAIZEN) to improve itself. The conclusion of this project is that in company which uses boring tool, can be assessed to be multipoint tool. In this we have to adopt the situation to eliminate the piston bore over size for using single point tool. The purpose of changing the tool has bestowed good surface finish inside the carburetor.

\section{REFERENCES}

1. https://www.slideshare.net/sathyanarayana_gandhi01/new-project14703656

2. https://www.slideshare.net/manmit111/boring-machine-ppt

3. Grafe, W., \& Held, P. (1983). U.S. Patent No. 4,367,991. Washington, DC:U.S. Patent and Trademark Office.

4. Martins, J. (1982). U.S. Patent No. 4,340,327. Washington, DC: U.S. Patent and Trademark Office
5. Kawai, I., Uchida, T., \&Ishima, K. (1974). U.S. Patent No. 3,784,173. Washington, DC: U.S. Patent and Trademark Office. 